\title{
AN EXPERIMENTAL STUDY OF SOME PROBLEMS OF PERCEIVING AND IMAGING.
}

\author{
By F. C. BARTLETT. \\ (From the Psychological Laboratory, University of Cambridge.)
}

1. General introduction.

2. Method of experiment.

3. Description of experiments and of results :

(i) Series 1, Simple diagrams and designs.

(a) Group 1,

(b) Group 2,

(c) Group 3.

(ii) Series 2, Kinematographic material.

(iii) Series 3, Simple concrete representations.

(iv) Series 4, Complex picture material.

4. Summary of results from Series 1-4.

(v) Series 5, Ink-blots and ambiguous outlines.

5. Discussion of results-Complexity of process of perceiving-'Effort after meaning'-Feeling and imaging-Changes in content of imaging - 'Feelings of relation' and the beginning of analysisClose relation of perceiving, imaging and thinking.

\section{Summary.}

[AT the outset I wish to express my indebtedness to those who have helped me in the preparation of this paper: to Lieut.-Col. C. S. Myers, R.A.M.C., who suggested the general subject of the investigation, afforded facilities for the carrying out of the experiments, and willingly gave valuable guidance throughout; to Prof. James Ward, who gave many suggestions with regard to the methods of experimentation, and with respect to authorities to be consulted; to Miss E. M. Smith and Dr W. H. R. Rivers, who read through the paper in typoscript and made a number of valuable criticisms; and to the many subjects who willingly submitted to the tests. What value the paper may possess it owes largely to the assistance that has been given in these various ways.] 


\section{General Introduction.}

It has often been pointed out that "perceiving is an act, a thing that we do, never a mere passive sensing of a group of passing sensations or impressions ${ }^{1}$." In the course of development this act may become very complex, so that a study of the factors that determine its nature may involve a reference to a number of processes that have been sorted out and named by psychologists. But always, wherever there is perceiving, there is a direction of attention upon an object that is to be regarded as being actually present.

This statement may itself, of course, give rise to various disputes. Is it really necessary that the object reference should be clearly made before what we can call perceiving may take place? What does "being actually present" mean? Can we find when and how a subject says of something distinguished from his own act of apprehension that it is 'here' and 'now'? These are difficulties which even the simplest statement of what is ordinarily meant by perceiving may raise.

But with these the present study has nothing to do. Its first part is concerned solely with ways in which adult subjects set about perceiving material of greater or less complexity that is presented to their observation, and with the factors determining these ways. The consequent limitations of the experiments have to be kept in mind throughout.

First nearly all the subjects examined were adults, and it has to be remembered that these brought to their task habits of observation that had already been formed by long process of development, and often set about the problems given to them under the influence of general attitudes which had been determined by much earlier experience. This all made analysis more difficult, and in particular it was necessary always to guard against the tendency on the part of such subjects to treat processes which could occur only as a result of considerable training as themselves simple and fundamental.

'Simple,' in fact, is a term that may have several different shades of meaning. In these experiments there is a simplicity of task, a simplicity of material presented, and a simplicity of factors present in the act of perceiving itself. Generally the term was applied to a task which, because of its familiarity or for some other reason, a subject found to be easy. Sometimes it was used of material which contained

1 Huey: The Psychology and Pedagogy of Reading, p. 104. 


\section{Some Problems of Perceiving and Imaging}

little detail. Again the term may be employed to indicate factors which appear to be constant throughout a whole series of experiments, and so to be required for all cases. It is often used also of factors that are definitely regarded as not capable of further analysis, as foundational in a historical sense, as original elements of the mental life. These different meanings may be readily confused; and particularly when a task set is easy it may seem as if the distinguishable factors involved are incapable of being further analysed. But in this respect ordinary introspection, as Professor Dawes Hicks ${ }^{1}$ has often pointed out, is liable to go much astray. A subject's judgment: "This is simple," must always be received critically. And in fact it cannot be claimed that experiments of the kind here described of themselves throw much light on the question of what is to be regarded as simple in a foundational sense.

Then also the inquiry into the various ways in which we set about perceiving was limited by the fact that the same sort of problem was put throughout. No doubt what Goldscheider and Müller found in the case of reading holds good generally. They said that when we read we perceive in various ways according as our purpose may be best secured. But throughout these experiments the nature of the problem set was constant. The question was simply one of giving an accurate reproduction of presented material. Changes of method therefore, when they occurred, were due to other factors than that of change of purpose.

Again probably the definite effort to reproduce accurately may have meant the adoption of methods and attitudes somewhat different from those of ordinary observation. This difficulty was of course unavoidable from the very nature of the experiments, but it had to be borne in mind throughout, and the results of the experiments checked, as far as possible, by reference to common experience.

The general problem therefore was to attempt to carry through a study of ways of perceiving, and of the factors influencing those ways and their results. It soon became evident that this would involve a study of the nature of imaging, for the two processes are commonly found together in a single act of observation, although they are of course to be discriminated.

1 See, for instance, his article on "The Nature, and Development of Attention": this Journal, vI. 7 :- “ It has to be borne in mind that what may appear to us introspectively, in our mature experience, to be a simple and unanalysable process, need not by any means necessarily be a simple and unanalysable process as a psyọhological tact." 
In perceiving there is always direction of attention upon an actually present object. It is always the object or some part of it that is known, but it is known, not in a literal sense immediately, but by means of present sensuous experience of some sort. Even in the simplest act of perceiving this sensuous experience is not treated as complete in itself, but as referring to 'something' which in later development gains for us all the marks of object ${ }^{1}$. In his description or representation of a given object however a subject, even from very early stages, frequently passes beyond what present sensuous experience justifies, and brings in characteristics which a more careful observation will show him do not belong to the object presented. Whenever that occurs there is imaging, though of course the subject at the time thinks that he is describing what is actually present to his observation. It is in this sense that imaging came into the experiments from the beginning, and not of course in the sense in which imaging means a characterisation of an object which at the time of the reference is regarded by the subject himself as not present to his sensuous experience ${ }^{2}$.

\section{Method of Experiment.}

The method adopted was as follows. Material was presented to the subjects, and they were asked to say what they had seen, or, in the case of the final series, what they had been reminded of, or had imaged. The material was graded in nature, and passed from simple designs and patterns to designs the structural complexity of which was considerably greater, to concrete picture material, and eventually to ambiguous outlines which were used in the study of processes of imaging. The presentation was made, in the case of some of the picture

I Cp. Stout: Manual of Psychology, 3rd edit., p. 132: "We must therefore assume that the simplest datum of sense perception from which cognition of an external world can develop consists, not merely in a sensuous presentation, but in a sensuous presentation apprehended as conditioned by something other than itself."

2 The term "imaging," therefore, is one to which a very wide extension is here attached. It may apply to all processes by which reference is made definitely to an object or to parts of an object in the absence of direct sense experience to guide the reference. It includes all the cases in which visual, auditory, verbal or any other of the commonly recognised forms of images are present; it may perhaps include instances in which none of these can be discriminated; and it covers all the examples of 'imagining,' in which our attitude is definitely a calling up of something that is 'not here.' But, as is indicated later, it is distinguished from thinking in that the latter deals primarily with relations and not directly with specific instances. 


\section{Some Problems of Perceiving and Imaging}

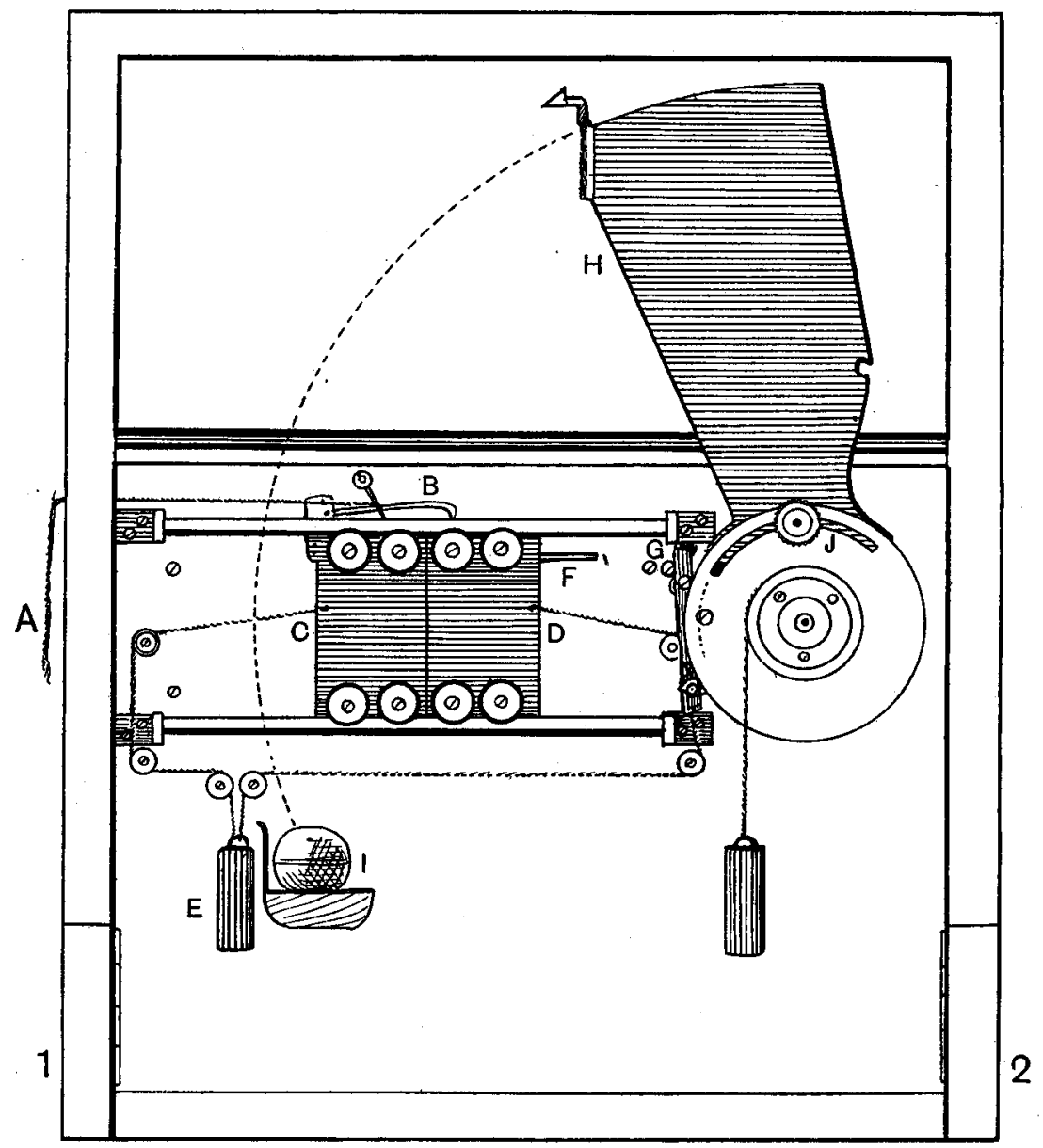

Fig. 1. The experimenter pulls the string $A$, and thus releases the catch $B$, which holds together the two shutters $C$ and $D$. The shutters are pulled back by the weight $E$, and the rod $F$, on the shutter $D$, hits against the lever $G$, on a small projection from which rests the shutter $H$. The lever is pushed back slightly, and the shutter falls into position in front of the open window, its fall being broken by the air cushion $I$. $H$ is held in position by the catch at the end of the shutter.

The tachistoscope is set up on an ordinary table, and rests on folding brackets at 1 and 2. The subject sits at the table on the other side of the shutters, with his eyes on a level with the window, and he sees the object-which in these experiments was placed upon a card rest set at the proper height-for the period between the running back of the shutters $C$ and $D$ and the falling of the shutter $H$. The distance of $H$ from the window can be adjusted by means of the thumb screw at $J$. The parts of the card rest can be screwed to the body of the instrument, and the whole folded so as to take very little space. 
materiat by means of the Hales tachistoscope ${ }^{1}$, and in the case of the designs and some drawings by means of a small portable tachistoscope which was specially made for use with these experiments, and which did satisfactory work throughout (see Fig. 1). The advantages of the smaller instrument were that it could be carried about and set up almost anywhere; it could be employed in daylight or with ordinary conditions of illumination; material could be introduced easily and as easily modified, while the fact that the shutters opened from the middle eertainly seemed to give the composition of presented material a better chance of producing its ordinary results.

With this instrument the commonest length of exposure used was about $\frac{1}{4}$ sec. In justification of the shortness of this it must be remembered that the ordinary glance of everyday life does not rest long on any given object, and also that the attitude of the subject in experiments in which he is definitely set to observe and to reproduce is far more keen and critical than it is ordinarily. A short exposure may therefore help to get near to everyday conditions. When the less simple figures were used, however, subjects often called for repeated inspection, and this was allowed. Repeated exhibition was resorted to also when it was clear that a good deal of a presented figure was yet to be made out. This, as a rule, began to be the case when the designs in Group 3 of Series $I$ were reached. In all such cases the subject attempted a reproduction after each exposure.

In the case of the simpler designs the subjects reproduced what they had seen by drawing it immediately after the observation. Often the drawing was supplemented by description, and whenever difficulty of draughtsmanship was experienced subjects merely described what they had seen. Few suggestions were made to the subjects, so that practically all the extra information given by them was volunteered, and must have consisted of features that seemed specially striking.

The material used falls naturally into series, and in what follows it is arranged roughly in ascending order of structural complexity. What appears complex to a subject however is not by any means necessarily that which contains the greatest amount of detail, and this order of structural complexity is adopted simply because it is convenient for purposes of arrangement.

A different method was employed for the definite study of acts of imaging. That however will be described later.

In connexion with the first four series thirty subjects in all were

1 See this Journal, Ir. 244.

J. of Psych. VIII 


\section{Some Problems of Perceiving and Imaging}

tried, though they were not all presented with the whole set of figures. All but one of these were adults, the one exception being a youth of fifteen. Six of the subjects were women. The persons who submitted to trial had very varied interests; six of them were from a small country town and their interests were chiefly practical; twenty-two were graduate or undergraduate members of the University of Cambridge, and the other two werè working-class men from a fairly large town.

For the tests on imaging thirty-six subjects were tried. Only four of these were children, and the rest were adults. They were diverse in interests as in the first group of tests.

\section{Description of Experiments and of Results.}

(i) Series 1 consisted of fairly simple designs and patterns. The figures used fall naturally into three groups, and in what follows a selection is given from the figures of each group.

(a) Group 1:

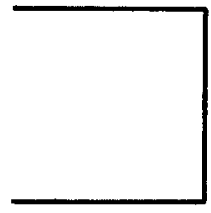

(i)

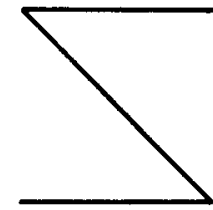

(ii)

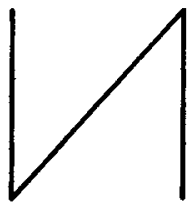

(iii)

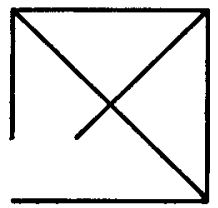

(iv)

With such simple figures as these the attitude of all of the subjects was practically the same. The designs were seen as wholes and were reproduced without hesitation. There was no attempt to analyse into parts.

Names were given very commonly indeed except in the case of (i), and even this was often called "a square with one of its sides gone." (ii) was said to be " $\mathrm{Z}$ upside down" (though it is not this of course); (iii) was called ' $\mathrm{N}$ '; and (iv) was a "square with diagonals." The names were generally given as soon as the design was exhibited, and they appeared to induce in the subjects an attitude of greater certainty and satisfaction. The tendency to give names persisted throughout the whole of the experiments, though it was much more marked in some subjects than in others. For diagrammatic material it was least used by those subjects who had been much occupied with mathematical study.

With quite simple figures there was no reliance on the name as a guide to representation. Though (iii) was called ' $N$,' it was correctly 
given by all subjects, and (ii) also was generally reproduced accurately. In all these cases the naming seemed to do no more than make the experience definite.

The gaps in (iv) caused difficulty. Whenever a design was given in which a gap or any unusual feature was present, it was common for the unusual characteristics to be noticed and reproduced, but there was great difficulty about determining their position within the figure.

This accords with common experience. We readily notice any unfamiliar feature in fairly familiar objects, or anything unmeaningful in figures that carry a common meaning. The familiar requires little attention. At a glance we interpret it. But a gap or an unusual line attracts and holds us. So we remember that it is, although we may forget where it is. The whereabouts, in fact, we can rarely give, because it is not the whereabouts that we attend to, but the gap or line itself. So most subjects were doubtful about the accuracy of their reproduction in these cases, and would say: "I know that this gap (or line) is there, but I am not sure where to put it." Partly, no doubt, this was due to the shortness of the exposure. But it is notable that the unusual should almost always be seen readily. Not all changes, however, appear to be equally noticeable, as results gained from the kinematographic material (Series 2) used later tend to show.

Even with the simplest figures interpretation tended to run beyond what was presented. Especially when a gap or line arrested attention there was a marked tendency to suppose that the rest of the figure was complete and of some common shape. Most subjects, for instance, gave the square of (iv) completely, but reproduced correctly the gap in the diagonals. The tendency to interpret what is not seen in the light of what is seen was more marked the greater the detail of presented material and the greater its familiarity.

(b) Group 2:

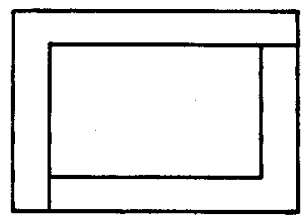

(v)

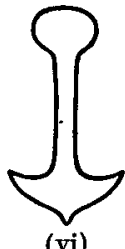

(vi)

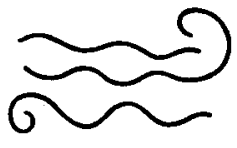

(vii)

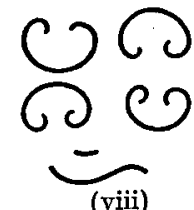

(viii)

The designs in this group contained slightly more detail than those in Group 1. Some of them, of which (v) and (vi) are illustrations, 


\section{0}

\section{Some Problems of Perceiving and Imaging}

were such as to suggest more readily representations of concrete material, while others-(vii) and (viii) are instances-were more meaningless, and were composed of more disconnected parts.

The attitude adopted in these cases hardly differed from that taken up towards the designs in Group 1. Always the attempt was to take in the figures as a whole, and to reproduce all of a given design after a single glance. Most subjects now hesitated a little longer before they attempted to put down what they had seen; and this tendency to pause increased with practice. In every case it was said to be due to the fact that in this way it was most easy to get a clear image of the object seen.

Naming now became of greater importance than before, in that it began to play a definite part in shaping representations. For example, (vi) once recalled a 'pick-axe,' and was represented with pointed prongs. Once it was called a 'turf-cutter,' and the blade was made very much rounded. It was said to be a mixture of 'a key-the handle-and a shovel-the blade.' Another subject remarked that he was reminded of a sign he had once seen at a railway station: "It was a picture of a spade, of two spades in fact, only they were not that way up. But this is more of an anchor." Five others also called the figure an anchor, and in these cases there was some tendency to exaggerate the size of the ring at the top. Curiously enough, only once, when the figure was called an anchor, was the absence of a crossbar at the top commented on. It is possible however that the exaggeration of the size of the ring was due to a vague apprehension that there was something unusual about the top part of the figure. That such vague apprehension is fairly common was shown clearly enough in connexion with figures used in Series 2.

Once only was the point in the blade of (vi) correctly reproduced, and on that occasion the subject said that the design represented 'a prehistoric battle-axe.'

Exactly the same function of naming came out in connexion with (v). Twice it was called a 'picture-frame,' and the reproduction given in these cases was
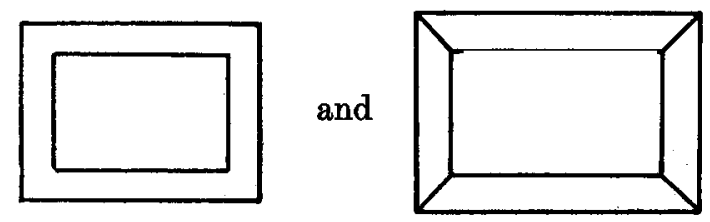
respectively. But the subject who spoke of it as two "carpenter's squares placed together" got the figure right at once. Another subject was reminded of a garden plot with paths round it. This of course did not help at all in the reproduction: "I am not quite sure," he said, "how the paths go." Indeed in this case it was the association rather than the figure that attracted his attention: "I was reminded of the sums I used to do; so many tons of gravel at so much a stone."

All this illustrates also how great a variety of names are likely to be given even to very simple figures ${ }^{1}$. The variety arises at least partly from the fact that what led to the name was usually a general impression, together with a definite observation of certain detail. The general impression suggested the nature of the whole given, and the detail was used to help in the interpretation of the whole. The direction of the interpretation was largely determined by some earlier experience of the subject. In that way features not present at all often came in, and present features were readily modified.

Goldscheider and Müller, in their account of experiments on the process of perceiving in reading, speak of memory as simply a way of functioning of the activity of apperception. Whatever the value of such terminology may be, it is certain that even with very simple figures, the process of perceiving was, in these experiments, shortened, and at the same time laid far more open to error, by the tendency to interpret presented material in accordance with the general character of earlier experience.

This itself however is just a way in which what seems to be more fundamental still finds expression. Always in perceiving there is present what may be called an effort after meaning. The exact significance of this will have to be discussed later on. Whenever material is presented there is a tendency at once to seize upon and to use any factor that will help to free the act of apprehension itself from an accompaniment of felt strain. Thus with familiar material there is immediate reference to the general nature of past experience, while if the material is unfamiliar other factors may be used to bring about the same result.

This leads to a consideration of the results arrived at with designs of which (vii) and (viii) are taken as illustrations. Both of these are relatively meaningless, and both contain disconnected parts. They

1 Cp. Quantz: "Problems in the Psychology of Reading," Psych. Review, Mon. Suppl. Ir. No. 1, p. 10 . " $\diamond$ is called a diamond or a rhombus; $O$ a circle or a globe; (s a moon or a crescent. This is returning to the indefiniteness of picture writing." 
gave more trouble than the other figures in the group, and subjects were generally dissatisfied with the reproductions they were able to achieve.

The difficulty was greatest with (vii), for there is an order of arrangement in (viii), and anything symmetrical is very quickly noticed by most subjects. That which is so much outside ordinary experience that it is hard to find for it a name, and which at the same time presents an apparently arbitrary mixture of lines and curves, most effectively resists the 'effort after meaning.'

Often however when figures in themselves appeared relatively meaningless they were given a sort of significance by analogy with other figures. And here the naming became, if anything, more important still. For the analogy had practically always to do with the shape of a figure, or with the disposition of its lines and curves. When (viii) was exhibited to a mathematical student, for example, he remarked at once: "That arrangement of lines reminds me of what is called a 'determinant." His reproduction was accurate after a single glance, and several weeks later he still remembered and reproduced accurately the shape of this figure. Analogies of this kind were frequently used. The fact that when interpretation is hindered in one direction it will work out in another helps to justify the use of the term 'effort after meaning.'

In spite of the difficulty of interpretation, the common attitude in perceiving remained the same with these figures as with those formerly used. Even when the figure was exhibited three or four times, subjects practically invariably tried to make out the whole at one glance. It would seem in fact as if there is a more or less conscious standard in such cases. When the structural complexity is not very great the attitude is: "I ought to be able to make out the whole at one glance." Accordingly the effort is made, and it is only after failure repeated that a piecemeal method is adopted.

Another point, many times illustrated later, was first noticed with (vii): the tendency to a multiplication of detail with disconnected material. In some subjects this tendency was very strongly marked ${ }^{1}$. They were instances of the persons who not only almost always try to take in everything at a single glance, but who are readily confident that

1 In discussion of this paper Dr P. B. Ballard made the interesting statement that he has found this tendency to multiply details common, constant, and very marked among children. This he found to be particularly the case among young children who were unable to count. Inability to count was of course the lot of all subjects in the experiments that are described in this paper; the shortness of exposure made definite counting generally impossible. 
they can give a fairly good reproduction. "In every case," said one, "I kept my gaze fixed on the screen for a few seconds after the window had shut down. I was trying to get a clear image of what I had seen, and in doing this I usually felt part of the design escaping me, while the rest set into a firm enough shape to be transferred to paper. The sense of having lost some part of the original may account for the general superfluity of the reproductions--a desire to make up for the bareness of the actual image by adding probable lines here and there."

Apart from this, there is, no doubt, in many cases, an immediate impression of crowded detail. The attempt is to take in at a single glance all of the features of whatever is given. But when these are more numerous than are readily apprehended or remembered they can be given only very hurried attention. The hurry itself suggests that there is more to be seen than is really given ${ }^{1}$, a general attitude is induced in which the subject says hopelessly: "I shall never get all that," and this again helps to heighten the impression of detail. The confident subject falls readily in with this attitude and gets down in his reproduction more than is to be seen; the cautious, hesitating subject reacts in the opposite way, and tends to diminish rather than to increase the details presented.

The importance of such general attitudes in determining the result of an act of perceiving will be further illustrated later on. They also are evidence of the way in which factors which are to be traced to the past life of an observer may affect the results of experimentation.

(c) Group 3:

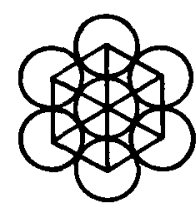

(ix)

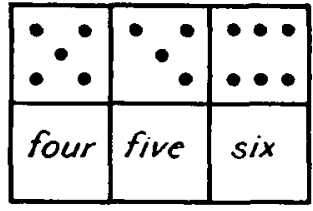

(x)

The designs in this group still formed readily appreciable wholes, but they contained rather more detail than the figures used hitherto. Some of them, of which (ix) is taken as an example, were such that it seemed likely that they would be best reproduced by subjects who grasped the plan of their construction. Others (e.g. $(\mathrm{x}))$ were

1 Cp. Emerson on Prudence: "The Latin proverb says "in battles the eye is first overoome.' The eye is daunted, and greatly exaggerates the perils of the hour." 


\section{Some Problems of Perceiving and Imaging}

devised in order to see whether, with material divided into parts, - - the parts themselves containing considerable or important detail-there would be any tendency to a definite change of method on the part of the percipient.

Design (ix) was called simple by some subjects and difficult by others. All those who called it simple were familiar with mathematical constructions; all those to whom it was difficult were unused to dealing with such material. Here came prominently into notice the factor of the general attitude involved. When a design was exhibited a subject's attitude would be either an easy and contented: "Yes, I've got that," or a puzzled: "I shall never be able to get all that." Often, indeed, the first attitude would turn into the second, and many subjects remarked that they were sure of the details of designs seen until they began to try actual reproduction, but apart from such changes the general attitude of ease or of satisfaction certainly affected the nature of the reproduction.

Here for instance are two attempts to reproduce (ix), both done in the attitude of "I shall never be able to get all this":
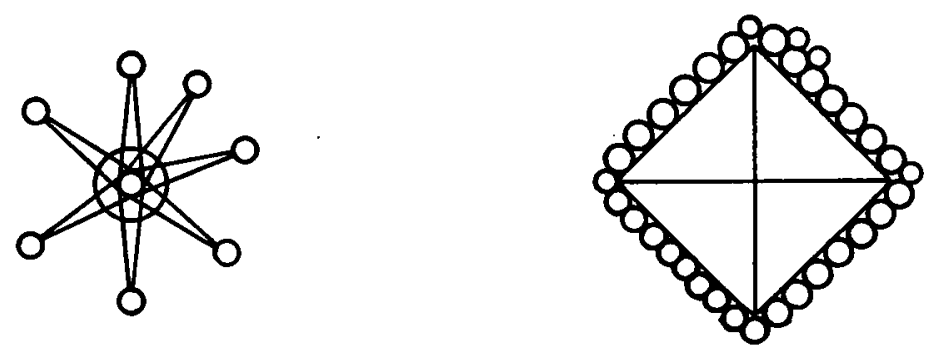

It was not pretended by the subjects that these' were accurate reproductions, but they were proposed as "something like what I have

1 The first of these was very probably partly due to confusion of (ix) with some of the characteristics of the figure given immediately before. This was:

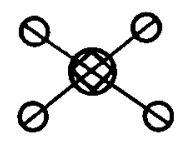

Professor Carveth Read suggests that considerations of this sort show that the experiments included much more than perceiving proper. The subjects did not see exactly what they reproduced. This is undoubtedly true, but it seems simply to reinforce the position that a very great deal of what we call perceiving in the ordinary way is enormously influenced by processes or acts of imaging, ramembering and the like. 
seen." It will be noticed that in both cases, and particularly in the second, the number of small circles has been considerably increased. Yet in the second case the subject said that his reproduction was fanlty because "there ought to be more circles in it."

On the other hand, to two subjects who were well acquainted with geometrical construction the figure presented no difficulties. They got the key to it at once, and reproduced it practically correctly at the first glance. What they said of it was "I know how it is made," and "I have been accustomed to that sort of figure for a long time. I know for instance that there must be six small circles round the middle one." In fact the general attitude of satisfaction with which they faced this design was practically the same as that with which most subjects met the concrete picture material of later series.

The change from satisfaction before reproduction was attempted to dissatisfaction when the attempt was made was no doubt partly due to the common swift fading of the primary memory image. But it was probably more definitely due to the fact that in ordinary circumstances there is very little need for accurate, detailed reproduction of what is observed. Ordinarily general impressions, as we call them, are far more useful to us than very detailed observation would be. Accordingly we may be perfectly well satisfied that we have quite well grasped the nature of presented material, though we may all the while have no clear apprehension of detail at all.

With $(x)$ came a very noticeable difference in the general method of perceiving. The single glance method having served tolerably well up to this point, it was always tried first when $(x)$ appeared. But invariably it resulted in failure. Then, on repeated exhibition, quickly in most cases, more slowly in others, a definitely piecemeal method of observation began to be adopted.

The general plan of the figure was commonly obtained at the first, though sometimes eight squares were given instead of six. There was never at first any certainty about the contents of the squares.

Then the small squares were taken one or two at a time till the whole figure was covered. Commonly, with this method of concentration, unless a part of the figure was definitely attended to, it was barely seen at all. Thus errors made concerning any particular square were left unaltered, even after repeated trial. If he was shown the design afterwards, and the error was pointed out, the subject would say: "I thought I had that right, and afterwards I did not look at it at all." Partly this was due to the shortness of the exposure, but it also fits 
in with the already noted tendency to rely for details on a general and ill-defined impression.

It seemed likely that there would be an effort to connect the words in the lower line of squares with the numbers of the dots above them. But as it turned out there was little or no tendency to do this. The common practice of taking each square by itself accounts for this result; and when the figure was seen as a whole there was very little discrimination of detail.

But one point was very clear, and that was the tendency to take the top part of the figure first. In $70 \%$ of the cases attention was given first of all to the top line of squares. The same was found over and over again with other figures in which the detail was rather too great to be clearly apprehended all at once. And particularly in the next series, when symmetrical material, arranged so that the bottom part simply repeated the top, was employed, the report constantly given was: "I saw the top only," or: "It was the top part I saw clearly." All this was a fresh illustration of the fact that, as Huey points out" : "we habitually find most meanings in the upper parts of objects; we ourselves are so placed and so oriented as to bring this about."

\section{(ii) Series 2, Kinematographic material.}

We pass now to a consideration of Series 2. So far there had been no definite structural relation between the various figures used, except that they were roughly arranged in an ascending order of complexity of detail. But now a series of designs was employed in each set of which there was a gradual increase or decrease of detail, the plan of construction remaining the same throughout. By the use of this sort of material it was hoped to make a little more clear some of the conditions under which definite changes in presented material are most likely to be observed, and to find what sort of changes are observed most readily. A single illustration will suffice to show the kind of design that was used. (See following page.)

The designs were presented either in ascending or in descending order of structural complexity. They were not all quite as regular in their changes as those given above; in some lines were dropped as well as added, in others symmetry was lacking, and in others the first or else the final figure was a representation of a common object, such as a bird or a crown.

\footnotetext{
1 Huey: op. cit. p. 99.
} 
The tendency on the part of all subjects to notice particularly the top parts of the figures, unless some special reason attracted them to another part, has already been mentioned, and no more need now be said about it.

Symmetry was noticed at once by all the adult subjects. "I got an impression," they would say, "that the different parts of the figure

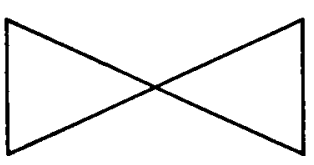

$a$

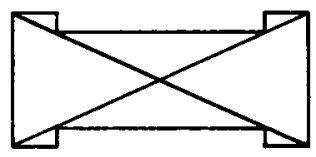

$d$

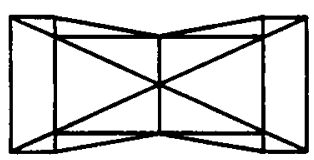

$\boldsymbol{g}$

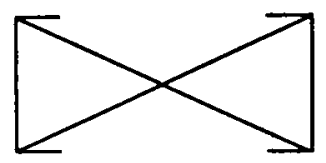

$b$

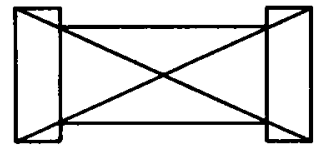

e

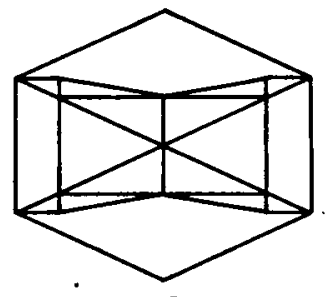

$h$

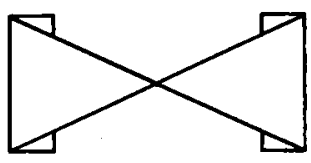

$c$

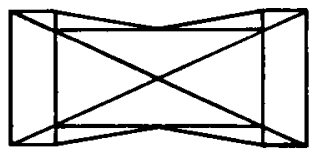

$f$

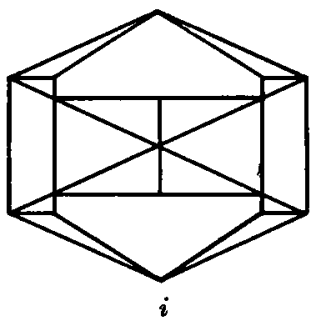

were alike." Symmetry certainly plays a large part in determining that composition of an object which is most easily and accurately perceivable. But the really interesting point was the use in this connexion of the very common phrase "to have an impression of." This, and the alternative phrase: "to have a feeling of" were often used of the perceiving of symmetry, of similarity, of sameness, of difference, of the 'progressiveness' of a series of figures, and occasionally of 'meaning' in the sense of some representation or other. And this 'feeling,' as subjects called it, was commonly made the basis of important inferences.

This was best illustrated in cases where a figure became progressively more complex, while its symmetrical nature was retained. "I got an impression," said one subject, "that the figure was symmetrical, though I did not notice the details. I built on that, looking for one addition 
or omission, and then inferring others in other parts of the figure." Another said: "I had an unconscious assumption"-he apparently meant precisely what others meant by 'impression' or 'feeling'--." that the figure was progressive, and relied upon that." And another: "I looked for some alteration as the different figures came. I had a feeling that the figure was growing more complex, and so I looked to see if anything had come in, and not if anything had gone out. I certainly did not see the whole of the figure in its later stages, and unless I had seen it in its simpler forms, I could not then have reproduced it at all." Thus there was a general impression of the composition of the figure, together with a definite noticing of certain parts, and an inference based on both resulting in a representation of the whole. Unless the plan of construction had already been firmly grasped, strict concentration upon detail was a downright hindrance.

Further evidence of the importance of the inferential element was afforded by the difficulty found with curves. "When you have a straight line," said one subject, "you know where it must go, and if you have an impression that the figure is symmetrical and notice two or three straight lines, you can join them up, and make something of what you have seen. But curves might go anywhere. You can never tell."

Even slight differences between figures, the mere omission or addition of a line, were readily noticed. This, as many subjects suggested, was due in part to the general similarity of successive designs. Subjects, having got the general ground plan of a figure, would assume that that remained constant, and look specially for differences, often of a particular kind $^{1}$. But not all differences were equally easy to notice. Of the fourteen subjects who tried this series, eleven considered that additions were easier to notice than omissions, one thought that they were equally difficult, and the remaining two "did not notice." It is not altogether easy to decide, because when the plan of progressive additions is adopted the figure is less complex to start with, and all its parts are easily discriminated. But on the whole the evidence of the reproductions shows that additions are more commonly noticed than omissions, and particularly are more likely to be definitely attended to, and their position accurately reproduced. When something is dropped out, the result is often that vague experience called by most subjects an 'impression' or 'feeling' of difference. Thus after having worked

1 Cp. Royce: Outlines of Psychology, p. 92, "In the effects of decorative art the similarities present, for instance the symmetries, help me to appreciate more definitely the differences of experience upon which the decorative effect depends." 
through the set of figures given above a subject remarked: "The base of the whole set was something like a box. When I got down my representations I could see I had left parts out. I had a vague idea of what was omitted. Each time I had a general impression of the whole figure, but some details always escaped me before $I$ got them down. On successive exhibitions I noticed differences without being able to say just what was different." That experience was common, but the indefiniteness of it was more marked with omissions than with additions.

Obviously, further experiments ought to be made to determine the readiness with which other changes are noticed. Never once, in any of these cases, did a subject fail to note, when a diagram was turned round or put upside down, that it was the same figure in another position.

It was noticeable how readily expectation arose upon the repetition of the same general situation. Two or three exhibitions of diagrams in which lines were added, and the subjects would definitely begin to look for additions. If something quite different from what had been expected turned up, the reproduction would suffer. Again, expectation arose readily whenever figures carrying a familiar meaning were presented. One of the sets was a drawing of a crown, the first figure of the series being as follows:

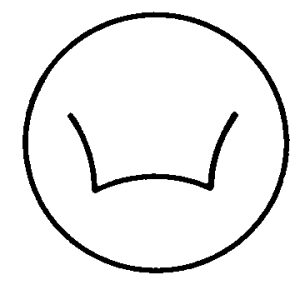

With the exhibition of the second figure:

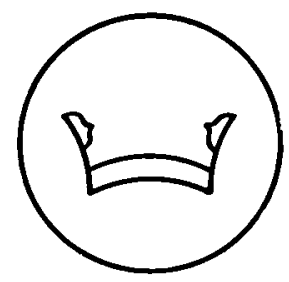

subjects began to guess what the final result would be, and at once to 
expect the nature of coming changes. The expectation did not work out into any close detail, but it did concern definite parts of the figure. "I was expecting something in at the top," a subject would say. Here again was evidence of the part inference may play in determining the general attitude and result in an act of perceiving. What was expected was a result of inference from what had been presented, and from the nature of earlier experience.

It was interesting also to notice how a complete figure was apt to appear more simple in construction than the same figure in an incomplete state. Over and over again the final crown was judged to be a less complicated figure than others which preceded it. As one subject put it: "The unity of the figure made it appear more simple." This sort of completeness of course is most likely to be carried by definite representations. It seemed to be based on the readiness of recognition which was thus made possible, a readiness which did not depend on the clearness with which details were discriminated. A subject who began with the most complicated figure thus remarked at once: "That is a crown," adding, "But I have not got nearly all the detail. I am going to draw my idea of a crown-a conventional crown-rather than exactly what was given." For all ordinary purposes in perceiving an object of this sort we never bother much about the detail, but perceive in accordance with a general idea which we already possess. In these experiments, such general ideas played the same function in reference to common objects for all subjects as did an appreciation of the plan of construction of a geometrical figure for the mathematical person.

(iii) Series 3, Simple concrete representations.

This leads on to a consideration of Series 3. Many subjects complained that diagrammatic material was uninteresting and to them unduly difficult. They were, they said, unused to dealing with such material. They suggested that they would get results more satisfactory to themselves if they were given representations of familiar objects. So another series was used, consisting of line drawings of common things or scenes. The following three reproductions will suffice to indicate the kind of material used.

This picture material was received generally with a very marked difference of attitude. Most subjects welcomed it with great relief. "I feel more satisfied that I have made out a picture of this kind," said one, "than that I have made out a design. I am no good at lines 


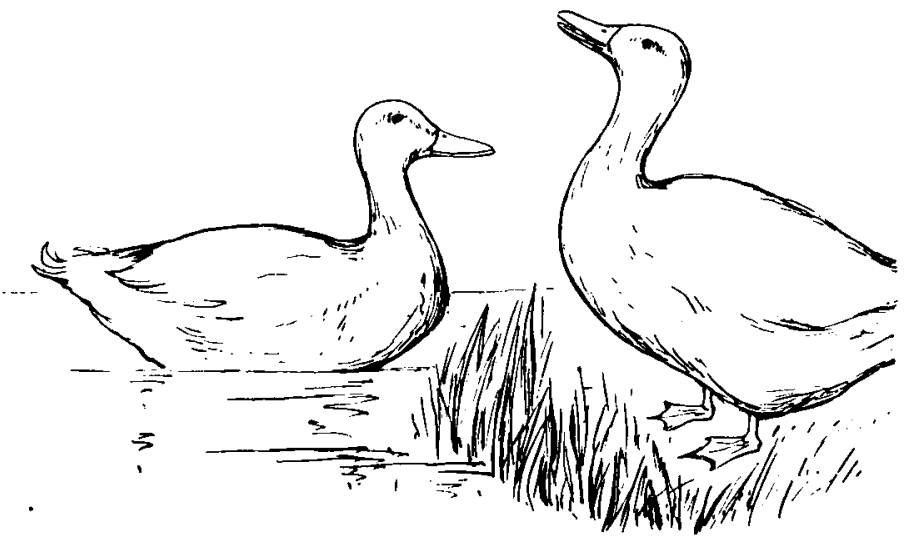

[Reproduced by kind permission of Messrs Harrap, English agents of Macmillan and Co., from Huey's The Psychology and Pedagogy of Reading.]
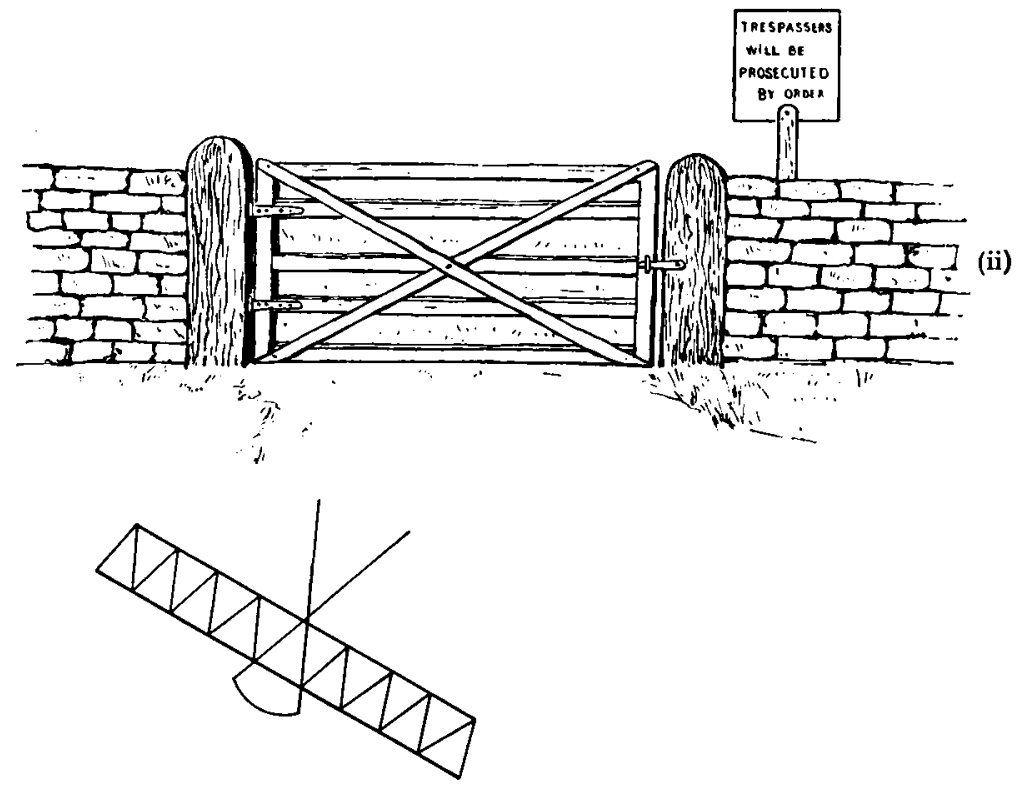

An Airoplaxe

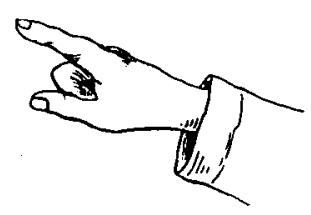


and circles because I am not used to them." And another: "Yes; that is better, I can easily get the whole idea here and I need not bother about the details." Twice, however, a preference for the designs was expressed, and in both cases the subjects were mathematical students who were familiar with diagrams. Their reason for liking the figures was of the same nature as that of the ordinary person for preferring the pictures. They grasped readily the plan of construction of a figure, while the ordinary person at once appreciated the general meaning of a picture. In neither case was strained attention to details called for, and that is just the position in most everyday acts of perceiving.

It is again clear from this that the figures which appear simple are by no means necessarily those which contain the fewest number of strokes, but rather those whose significance is the most readily interpreted. For the ordinary subject, who has no specialised interests, that means that the simplest material is either actual common objects or scenes, or representations of these. For the persons with specialised interests the simplest material is somewhere within the range of their particular bent; hence matter that appears to one person of enormous complexity may seem simple to another. And as far as perceiving goes, the simpler the object in this sense, the less likely is there to be any definite attention to particular details presented, and the more likely is the subject to rely largely on earlier experience for his interpretation of what is given.

With straightforward representations such as that of the duck scene above there was little difficulty. The general tendency was to see the picture as a whole at the first glance. The common description was very much like the following, which was given after a single observation:

"That is a couple of ducks. One has its head to the left and the other to the right. One is standing up and one is in a pond. There are reeds growing where the one is standing. They are rather big for ducks."

It is interesting that simple critical remarks, such as that of the last sentence, commonly came in at once. Drawings were called ' bad,' or 'rather effective,' or 'like a child's'; objects represented were commented on, and the critical comments often enough preceded the first description. The valuing attitude was in fact very closely connected with the act of perceiving itself. The tendency on the part of adult subjects to say something about material presented, as well as to say what is presented, was coming out all the way through. It was by no means confined to people well versed in contradictoriness, 
as philosophers or psychologists, but was just as much marked in people with practical and open-air interests who submitted to trial. In fact the valuing may quite well be called a part of the total act of perceiving, whether it takes the form of an unspecified satisfaction or dissatisfaction, whether it stops short at a mere "I like (or dislike) that," or whether it proceeds to definite criticism of details. Just as for all of us in practically all cases there is a general rule or plan helping to determine how and what we perceive in a given case, so also there grows up a tendency to accept, or reject, or anyhow in some way to criticise, whatever is presented, and this also plays its part in determining the result of an act of perceiving. By adult subjects the valuation, when it is applied at all to details, is generally carried out through a kind of comparison of what is presented with a rather vaguely recalled standard or conventional representation, as in the duck case above. The comparison is not, of course, definitely recognised as such by the subject. It has its origin on the feeling side of perceiving, though it may seem to get entirely free from that with the growth of experience.

The other two examples here given help to bring out the considerable influence of already acquired knowledge, concerning the nature of the general situation presented, in determining the result in perceiving.

In (ii) the point of interest was the notice-board. This was generally seen at once, but the writing on it could not be distinguished. With repeated exhibition subjects concentrated on the writing, but in no case did they succeed in reading the words. Practically always however suggestions were volunteered.

Eight subjects out of ten guessed that the board contained "Trespassers will be Prosecuted." One said: "I seemed to see it vividly. It is foolish, I know, because I can't read the writing, but I seemed to see 'By Order' written underneath." Once, influenced, he thought, by the closed gate, a subject gave "No Road" as the sign, and another gave "Keep off the grass." The last subject at once added: "I wonder why I gave that. It doesn't look as if it would be that, of course; it is much more likely to be 'Trespassers will be Prosecuted." The reason commonly given for this choice was that most boards seen in such a position are found to contain that inscription.

In (iii) the details were purposely left disconnected and the representation made far from definite. In all cases but two however the suggestion of an aeroplane came at the first or second glance. Usually a subject was at first not quite sure. The relative unfamiliarity of the main figure attracted his chief attention to that. but there was 


\section{Some Problems of Perceiving and Imaging}

almost always, at the same time, an impression of something undetermined on the left and right beneath. Later attention was turned to these features. In every case but one the writing was said to be 'An Aeroplane.' The misspelling was not noticed. Once a subject made out the writing before he named the main object, but in all other cases the reverse order was followed. In one instance only was the word read correctly, and this was the case of a man who had already seen the figure several times without being able to make out what it was. $\mathrm{He}$, that is, turned to read the words with no idea whatever concerning what sort of object was represented.

One subject only failed to see the hand as a hand. His failure was interesting, for it further illustrates the importance of a general topic or interest for the act of perceiving. He said: "To the bottom, on the right, is what I take to be an upraised cannon pointing at the aeroplane." The experiment was carried out, it should be noted, at a time when German air-raids were common, and one upon the town in which this subject was living was quite within the bounds of possibility. Moreover this subject was primarily interested in engineering.

What was seen therefore of material in this series depended largely, as in the other cases, upon a general impression, gained from a first glance, of the plan or topic of the object given. But while in the diagrams the main factors were such as those of symmetry, the greater definiteness of straight lines as opposed to curves, the likeness of figures presented to familiar geometrical designs, and here and there the representational value of the figures, with concrete picture material the main determining factor throughout was the meaning carried by the objects presented as representations, and the meaning itself was often fixed by the subjects' constant or transitory interests.

One noticeable feature of all these series ought here to be mentioned. In many cases when repeated inspection was called for, the opportunity was taken to substitute for the original figure one in which some detail was added, or omitted, or into which some other change was introduced. The details of results must be left for more comprehensive treatment, but one common fact must be noticed. Subjects were able to appreciate very slight differences, but even when the differences were most clear, there was a strong tendency to refer them to original faulty observation, and not to change in the object itself. For instance seven dots were arranged in a certain order on two cards. On one card all of the dots were red and on the other three were black. When the second was substituted for the first, every subject noticed the difference, but not 
one at first attributed it to any change in the card itself. They were surprised at the change, nevertheless they at once thought that their original observation had been wrong. It was only when the alternation had been two or three times repeated that they judged that two cards were being used.

This strong tendency to refer change in sensible appearance to faulty observation seems to be largely due to just those factors which lead also to great variety of interpretation of the same material.

(iv) Series 4, Complex picture material.

So far all the pictures used were simple in construction, and contained relatively little detail. In experiments carried out with a somewhat similar purpose by Mr Frank Smith (see This Journal, vI. pp. 320-362) concrete picture material rather detailed in nature was exposed by means of the Hales tachistoscope. It seemed desirable to complete the passage from structurally simple designs to really complex representations, and accordingly pictures containing much more detail than those used in Series 3 were employed, and these constitute Series 4. For most of them the pendulum tachistoscope was used as a means of exhibition.

There are, however, objections both to the use of this sort of material and to the method of exhibition, and it is rather as forming a very good introduction to the definite study of imaging that the results of this series are here worth consideration.

When the pendulum tachistoscope was used it was often found difficult to get a clear definition of the objects represented, except with a rather small picture. Some subjects also are troubled by having to stay for a length of time in a dark room. In any case the method of presentation does not put a subject into any thing like a normal situation. We do not commonly have to make out complex pictures or scenes by a series of flashes $\mathbf{1}$. We may, of course, often enough observe, by a number of rapid glances, a landscape through which we are passing. But in that case we are not anxious for accurate reproduction, and we rarely need to observe closely. It does not seem safe to say that the flashing up and out of a scene can give a result at all comparable to the continued observation of that scene, even when that observation

1 It is true that momentary exposures were used throughout, and that to some extent this method is bound to tend to produce an unusual attitude in the observer. But the difficulty arising in this way is less marked the less complex in structure is the material given to be observed. 
passes from detail to detail. Thus the problem set by these experiments hardly ever approximates to any problem set in the course of ordinary observation. The methods adopted by the various subjects may therefore be passed over rapidly, seeing that probably they are largely determined by the peculiar conditions of the experiment.

The main points of interest are:

(1) In all cases the first glance or two was used to gain the general meaning of the picture. The earliest description generally contained a good deal of detail, but the subject was guarded and doubtful about this. With unfamiliar scenes attention was turned upon detail more quickly and definitely than in the cases in which the presented material was familiar. The composition of the picture was important; a central figure quickly attracted attention and other details were grouped around this.

(2) Later observation went definitely to detail. Some subjects were more systematic than others in the way in which they explored what was given. These however did not get any more accurate results than the rest. Commonly details were interpreted in the light of the idea of the whole gained at first. In detailed observation subjects generally asserted that only that part of the picture was seen to which attention was specially directed.

(3) There was generally a period of increasing dissatisfaction with interpretations. Certain details were seen to have been observed wrongly, and doubt spread over the whole. Generally this passed with repeated trial, though at times it remained to the end.

(4) Associations of various kinds were very common, and usually increased in the later stages of exhibition of a particular picture. For then, as subjects said, they had: "seen the thing so often that there is nothing much else to think of."

But it is more interesting to study the extraordinary differences of interpretation placed by different subjects on the same material. Variety in interpretation tended to increase throughout with increase in the amount of detail presented. The greater the detail the greater is the tendency to pass from what is seen actually to a construction of what is seen only imperfectly, or is not noticed at all. Imaging comes in more and more. The pictures now used were all rather full of detail; the subjects knew that they were expected to make something of them, for they represented concrete scenes, while the fact that the experiments took place in a dark room meant that there was practically nothing beside the presented picture to attract the subject's attention. 
All this may have tended to increase greatly the part played by acts of imaging.

The most striking illustrations of this were given in the different interpretations placed upon a representation of the well-known painting of "Hubert and Arthur," by W. F. Yeames. Every person who was given this picture to describe made of it something different from everybody else. A few cases may be given. Repeated observation was always found necessary.

At the first glance subject A. said:

"It is a woman in a white apron with a child standing by her knee. She is sitting down and has her legs crossed. She is on the right of the picture as I see it, and the child is looking at her."

At the second attempt he said that the woman was standing up, and then, during thirteen trials, made few alterations and added very little detail. At trial 16 he said: "I had a vague feeling that I've seen it all before somewhere. But I don't know where, and I'm not sure what it is." At the next attempt he spoke of a "girl" leaning forward, and "stretching upward towards her mother-well, towards the woman." Further details were given, and then, at trial 25 he remarked: "Now I can see. The picture is that of a little girl saying her prayers on the other side of her mother's knee away from me. I mean she is kneeling on her mother's knee. She is dressed in a nightgown. The length of the night-gown made it look as if she is standing."

The picture was given thirty-eight times in all, but there was no further change in the general idea of the interpretation, though further details were given. The subject said that he had seen the picture in somebody's bedroom a long time before.

Subject B. at first saw simply two figures, but at the third attempt he said: "Yes, there are two figures. One of them seems to be leaning back a little, and the other is struggling with him, or is about to struggle." Thereafter the story was one of development of the idea of two persons wrestling. A "dark fellow" was made out, and was said to be "getting the worst of it." This subject saw the same picture fifty-five times.

Subject C. began in much the same way:

"I saw nothing definite, but merely a sort of contrast of black and white. There was something very like a white shape wrestling with a black one." At the second attempt he got his general setting. "Evidently it is a room with a black or shaded side to the right, and windows or else a highly illuminated part to the left. There was a black figure turning towards a white one. It was like a representation 
of Othello saying to Desdemona 'Come fly with me.'" There were alterations, and great additions of detail, but the subject stuck to this general idea throughout fifty-seven different observations.

Subject $\mathbf{D}$. began very confidently:

"It is the interior of a house. There are three figures. One is tall, the second less tall, the third less tall still. The figures are leaning against a pillar or wall. Probably I am looking at a copy of some old master. It might very well be "The Woman taken in Adultery.",

But he soon withdrew this, and said that there were only two figures. He suggested that the picture was one of "Charles $I$ and Henrietta," and to this he adhered through the rest of the trials, not however with any degree of confidence.

Repeated observation with varied material brought out the same thing over and over again. A simple silhouette picture of a man with a bundle of sticks on his back, leaning slightly forward towards a dog that is running just ahead of him, with a fence, a few trees, and a building in the background - the whole in white - was greatly changed by one subject.

"I seemed," he said, "to see a queen, and a man bending down over her. The queen seemed to have a crown on her head. There were boughs of a tree about her, and they seemed to be covered with frost." And then: "Yes, it is a prince bending down beside a queen. $\mathrm{He}$ has his head thrown back, and is looking up into her face. The dog must be a mere pet just walking along. It is cold." And once more : "She is dressed in costly garments. It seems to be one of the oldfashioned pictures. It reminds me of fairy tales and things like that; of adventure stories."

The last example shows how readily critical remarks (e.g. "it seems to be one of the old-fashioned pictures") and associations got mixed up with actual descriptions. Nobody else interpreted this card in quite the same way, but all such cases as the one given are certainly instances in which, to use the terminology of Avenarius, "Energie > Reizung."

Sometimes the picture exhibited called up representations of definite scenes. The best illustration of this occurred when one of the subjects, whose home was at a seaport town, was examining a picture of "Margate Lifeboat on the Slips." From the first he was troubled. At the 18th trial he said: "It is no use my going on. All the time I am getting a suggestion of the docks at home. And they are what I see, not the picture in front of me. One of the first things I did when I got a camera some time ago, was to take a view of that spot at home that 
I was reminded of when I saw this. There was a ship of heavy freight there at the time, just as there is in the picture here. So I'm always confusing the two, and I shall get no more out of this."

This difference of interpretation, present to some extent throughout the whole of the investigation, but rising to its height so far in the series just described, is the point now of chief importance. It means that, in the interpretation of presented material, imaging, in the sense spoken of at the beginning of this paper, may play a prominent part. It therefore seemed worth while to attempt the study of a further series, which should be designed specially with a view to arousing acts of imaging; and for this to use outlines that might suggest many things, but that definitely represented nothing.

Before however the results secured from the use of this material are described, an attempt must be made to sum up the main points of interest that arise from the study of methods and factors in perceiving carried out with Series 1-4.

\section{Summary of Results from Sertes 1-4.}

As to methods:

Methods adopted in perceiving varied with variation in the material given to be perceived. When presented material was comparatively simple in structure; when its parts were so clearly related by connecting lines that they formed readily appreciable wholes; when it was already familiar to the subject; or when it carried a common representational meaning, the general method was to attempt to make out the whole at a single glance. But with unfamiliar, or disconnected, or relatively detailed material the tendency was towards a more analytic method. The latter method was more readily adopted with complex diagrams of a geometrical character than with concrete picture material, except with those subjects who at once grasped the rule of construction of diagrams. The method of analysis was also more marked upon repeated exhibition of material. Then, commonly, parts only of presented material were definitely observed at any one glance, though most subjects had also what they called a 'general impression' of the rest. As in these experiments the purpose remained constant, nothing can be said with regard to the relation of dependence sometimes asserted to hold between change in method and change in purpose. In fact in these instances the change of method occurred most readily in those subjects who kept the constant aim clearly before themselves all the 


\section{Some Problems of Perceiving and Imaging}

time, so as quickly to adapt themselves to any change in the material. The experiments show that a 'set' or habit of perceiving grows up very quickly indeed in adult subjects, and in the absence of definite decision.

Except in the simplest cases, the method adopted showed a close blend of perceiving and imaging. For reproductions often depended on inference from general impression and specific observations, and commonly contained detail which subjects admitted that they saw only imperfectly, and often something that was not present at all. 'General impression' may mean appreciation of a plan of construction-as, commonly, with designs-or of the subject of representation-as with concrete pictures. For ordinary subjects it is most important in the latter case. It greatly increases the rapidity possible in perceiving, but is unfavourable to accurate reproduction. Ordinarily however there is little need for very definite and accurate reproduction, and so reliance upon inference is often extremely important in everyday acts of perceiving.

As to factors influencing methods:

First there are those that may be referred to characteristics in presented material, and secondly those that may be referred to characteristics of the subjects themselves. There is close relation between the two.

Of the first class $(a)$ with figures and diagrams:

(1) Symmetrical arrangement was found to be readily appreciable and favourable to correct reproduction. It was rarely observed in detail, but subjects would have an 'impression' of symmetry.

(2) With structurally complex material there was a tendency to observe the top parts of figures in most detail.

(3) Any novel features in presented material, particularly unusual gaps, were generally noticed, but their nature was more accurately reproduced than their position.

(4) Additions to a ground plan with which a subject was already familiar tended to be more readily reproduced than relatively equally great omissions from such plan. They were generally noticed as additions, and their precise nature was fairly well reproduced. With omissions, although difference was noted easily, the specific change was less readily given.

(b) With concrete picture material:

(1) The most important factor in helping towards successful perceiving was the arrangement of material in such a way as to form a readily appreciable whole of meaning. 
(2) With detailed material composition was important. The most favourable arrangement was that in which there was a prominent central figure round which the other details could be grouped.

Of the second class:

(1) Most fundamental was the constant 'effort after meaning.' This accompanied and helped to direct all cases, but it is not to be identified with 'felt strain,' and does not necessarily imply the presence of such strain.

(2) There was a marked tendency to criticism or valuation, and this was definitely connected with the feeling that accompanied all acts of perceiving. In its simplest form it consisted solely in a general attitude of ease or of hesitation, but it readily expressed itself in the more definite forms "I do (or do not) like this," and in critical remarks about the designs or drawings given. The tendency to valuation was connected with the ease with which meaning was attached to figures, and with the nature of the meaning attached.

(3) What was made of the given material depended greatly upon the prior experience of a subject, and upon his constant interests or those of the moment.

(4) This reliance upon prior experience helped to produce great variety of interpretation, and may also be connected with the strong tendency to refer change in sensible appearance to faulty observation instead of to actual change in the object.

(5) It was common, particularly in subjects with no developed abstract interests, to give names either directly or by analogy to material presented. In many cases the naming helped to fashion the representation.

(6) When there were more details than a subject could readily make out at a single glance, and purticularly when no plan of construction was grasped, there was a marked tendency, constant in any one subject, towards multiplication or diminution of detail. Closely connected with this were: $(a)$ the attitude of dissatisfaction, $(b)$ the swift fading of the primary image, and (c) the fact that ordinary observation is merely hindered if it concerns itself much with minute detail.

In several of these cases it is clear that factors that are of importance in determining the result of an act of perceiving may lie outside the limits of the act itself, and of these experiments. 
(v) Series 5, Ink-blots and ambiguous outlines.

Series 5 consisted of ink-blots and ambiguous outlines.

The possibility of using ink-blots in connexion with a study of the imagination was suggested by Dearborn in The Psychological Review, Iv. pp. 390-1. Material of this kind has been used by Dearborn himself in a brief "Study of Imagination" (American Journ. of Psychol. 1898, pp. 183-190); by Kirkpatrick in "Individual Tests of School Children" (Psychological Review, vIr. pp. $271 \mathrm{ff}$.), and by Miss Sharpe in certain studies in "Individual Psychology" (American Journ. of Psychol. 1899, pp. 329-391). The material seemed to be very well adapted for bringing out certain of the factors in imaging, and therefore a series of blots was prepared, some of which are reproduced in the accompanying plates. The numbers here assigned to the blots do not correspond with the order in which they were presented.

Thirty-six blots were used in all. They were variously shaded or coloured, and were all on ordinary postcards. These were laid face downwards in front of the subjects. The instructions were:

"Here are a number of ink-blots. They represent nothing in particular, but might recall almost anything. See what you can make of them, as you sometimes find shapes for clouds or see faces in a fire." The subjects turned over the cards for themselves. The time of their reaction was recorded and was reckoned from the turning up of a card to the moment when the subject began to write down what was suggested.

Methods adopted may be described briefly. It has been noticed already how quickly a particular habit of carrying through a task set tends to arise, even in the absence of any defined plan. This found fresh illustration here. Nearly all of the subjects soon got into the habit of looking at the blots at arm's length, or of putting them farther off still. Several remarked, "It seems easier when I do this." The point.is important because in the initiation of many ordinary processes of imaging clear cut definite details appear to play little part. It is in relation to that which might be many different things that images most readily arise, although at the same time the image itself tends to be of something in particular.

Suggestions made were commonly gained at the very first glance, though often some time was spent in elaboration. Times of reaction varied from less than a second to slightly more than a minute, but most cases of lengthy reaction were due to a subject's searching for the right word, or spending time in developing a vague suggestion already 
present. Sometimes it was the general shape of the blot, and sometimes it was an outstanding feature that played the chief part in determining the suggestion.

The most definite description of method was given by the subject who said that he 'rummaged about' amongst his images to find one that would fit a part of a given blot. He projected the image on to the blot ${ }^{1}$. If he got it to fit, and there were still parts of the blot uncovered, he tried other images as nearly as possible related to the first. In all cases the blot appeared to him as a whole. In this way he got often, as he said, scenes which he himself recognised as being quite absurd. Thus blot 13 on Plate II reminded him of " a lanky boy and a jester watching the antics of an inebriated abbot ${ }^{2}$."

Most subjects were far less definite, and a study of the results suggests that the most general case was that a blot presented immediately suggested a situation or a class of things, and that the rest of the work was further to specify this.

In the case of blots with several distinct parts there were wellmarked constant differences between those subjects who saw them as a whole and those who took them merely as a number of different blots.

We turn now to a consideration of the nature of the suggestions made. First their general characteristics will be described, and afterwards an attempt will be made at classification on the basis of differences between groups of lists furnished.

The most immediately striking feature of the results was their enormous variety. Hamlet's swift changes of fancy about the cloud ${ }^{3}$ were nothing to the varying verdicts of these subjects. What to one

1 The method of this subject could be more minutely described. First he thought about an object or a situation. Then, in his case in the visual form, he called up an image of some particular instance and this he tried to fit to the blot. The thinking about, which was quite common, is not to be regarded as itself necessarily involving an image in the ordinary sense.

2 In general those subjects who took the blots as wholes got far more fantastic suggestions than those who split them into parts, and took each part by itself. Another person, for instance, found that blot 13 suggested: "In the middle the top of the apple tree; on the right the Devil with his horns; on the left Adam, and Eve in the distance."

3 See Hamlet, Act III, Scene 2 :

Ham. Do you see yonder cloud that's almost in shape of a camel?

Pol. By the mass, and 'tis like a camel, indeed.

Ham. Methinks it is like a weasel.

Pol. It is backed like a weasel.

Ham. Or like a whale?

Pol. Very like a whale. 


\section{Some Problems of Perceiving and Imaging}

was a 'camel' (blot 2) to another was a 'tortoise'; to another a 'dug worrying a table-cloth'; to another 'two dead ducks and an ostrich'; to another an 'octopus'; to another 'a baby in a cot with a doll falling out'; to another a 'picture of Sohrab and Rustum in a book of Arnold's poems.' The uninitiated would hardly suspect that the following are all attempts to describe the same object:

'Irate lady talking to a man in an arm-chair; and a crutch';

'Bear's head, and a hen looking at her reflection in the water';

'Angry beadle ejecting an intruding beaver which has left foot-marks on the floor';

'A man kicking a football';

'Lakes, and green patches of meadow-land';

'Scarecrow behind a young tree';

'Stockinged foot. Bear with a cigarette in its mouth';

'Tiny partridges newly hatched';

'Animal pictures, and the Crown Prince of Germany';

'Smoke going up.'

These were all given for blot 12, and they were given in no spirit of perversity, but seriously, so that the subjects were quite willing to point out how extremely justifiable all their suggestions were.

With blots possessing simpler outlines the variety was commonly one of detail rather than of general idea. For instance blot 1 suggested something of the bird or of the fish to twenty-seven out of thirty-three subjects, but only twelve agreed to call it a duck; three thought it was a goose, two a cock crowing, one a turkey, while three were content to call it a bird without further specification. Similarly with blot 3 which is the most regular in shape of them all. Twelve subjects out of thirty-six called it a seal, six suggested a snail or a slug, four more thought it was a mermaid. The other suggestions were: 'fish' (2), 'whale,' 'young shark,' 'dragon with no legs,' 'cobra,' 'newt,' 'jelly bag lying on its side,' 'Roman lamp,' 'man lying in a sack,' and 'tadpole.' Two subjects made nothing of it.

With blots more irregular in outline the variety extended to the general situation itself. Two subjects only, out of twenty-three, agreed to call blot 9 a 'lady falling down.' No two persons agreed in their interpretation of blot 12 , and the same may be said of most of the blots in the series that were similar in shape to these.

Subjects frequently noticed the very common suggestion of animals. The total number of suggestions obtained was 1068 , and of these 635 were of some animal or of a human being. Many of the others were of plants, and in a large number of cases scenes were suggested in which animals or men played a part. Thus inanimate 
objects came very rarely into the lists. The frequency of animal suggestions was most marked of all in connexion with the blots which were more simple and more of a 'whole' than the others. Here $72 \%$ of the attempts definitely gave animals. Several subjects suggested that the reason was that outlying streamers or points first caught attention. These readily suggested motion and so life. Besides, as one said: "it is living things that are most noticeable and most interesting."

It has of course been noted before that this sort of test may throw a good deal of light on a person's interests and perhaps on his occupation. The subjects themselves often called attention to this. "You ought to be able to tell a lot about a man's interests and character from this sort of thing," they would say. It was a woman, for example, who gave 'bonnet with feathers,' 'blanc-mange,' 'piece of velvet,' 'fursmarabout,' 'piece of shot silk' (twice), 'ostrich feathers,' and 'crossstitch work,' in her list. The subject who was reminded by one of the blots of "Nebuchadnezzar's fiery furnace, with two men on either side at the top, and two in the middle" was a parson; while the same blot reminded a scientist interested in physiology of "an exposure of the basal lumbar region of the digestive system as far back as the vertebral column up to the floating ribs." Many other illustrations of the same kind of thing might be given.

Apart from special interests, it was common to find that when a subject had once got a certain type of suggestion he would run a good deal on this. One subject saw a man's face in one of the later blots of the series and thereafter to the end he tended, to his annoyance, to see a face in every blot presented. Another, at the end of the trials, said that what struck him most was his tendency "to get a line and then to stick to it." To some extent however this is no doubt due to actual appearance of similarity among the blots themselves. Instances of this kind of persistence of a topic are: 'ghosts,' 'mure ghosts kissing,' ' more kissing,' 'green ghosts'; and again: 'picture of an ornamental garden with a colossal statue of a man in evening dress,' 'valley between two hills,' 'valley ending in a bridge,' 'valley seen through a bridge.'

These are the most notable common characteristics. An attempt must now be made at classification based on differences between groups of lists.

This might be done in the common way, by a division of subjects into types. But separation into types, though it is of considerable practical value, solves no theoretical problem. The relatively set ways of reacting which are illustrated in types have practically always been 
acquired gradually. Whatever has a history presents a problem. And it is no solution to stop the history at some point or other and give a name to what is found. The really interesting thing is to try to show how the different characteristics that are found together in a 'type' are connected, and in what way they have probably grown up. While, therefore, we are unable to do without reference to 'types' whenever a problem of classification arises, the finding names for classes is always merely a preliminary step. It must be followed by a discussion of the relations of characteristics that constitute a particular class, and of the ways in which those characteristics are re-grouped, and perhaps greatly modified, in other classes.

Taking the whole of the results secured, the subjects may first be divided into those (Class 1) whose suggestions were generally particular in nature, with much specification of detail, and those (Class 2) whose suggestions generally referred to no particular object and to no special time. This is not really a hard line of division, because the second class is merely a further product of the same factors that give rise to the first; but it is a sufficiently important distinction to form a basis for classification.

The first class calls for subdivision, for there were: $(a)$ those subjects whose lists contained much actual reminiscence, and $(b)$ those whose suggestions did not often refer to personal experience, but were nevertheless generally made strictly particular. Both $(a)$ and $(b)$ represent a stage of imaging proper, but probably the first is more primitive than the second.

No list obtained consisted solely of suggestions belonging to one class, and only a somewhat rough tabulation of results can be given as follows:

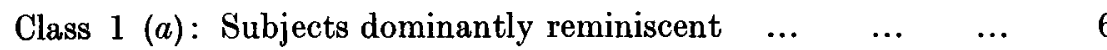

Class $1(b):\left\{\begin{array}{cccc}\text { Subjects occasionally } & \text { reminiscent and } & \text { tending } \\ \text { generally to definite particularisation } & \ldots & \ldots & 5\end{array}\right.$

Subjects whose tendency to particularise was marked, but who rarely appealed to memory... 10

Classes 1 and (Subjects who either particularised readily and 2 (mixed): $\{$ generalised less readily, or generalised readily $\begin{array}{lllll}\text { and particularised less readily } & \ldots & \ldots & \ldots & 6\end{array}$

Class 2: Subjects whose suggestions were dominantly general $\quad 9$ 
For the subjects in Class $1(a)$ nearly all blots of course represented particular objects or scenes, and most of them recalled definite events in personal history which were reinstated in visual or other imagery.

Take, for example, these remarks made by one of the 'reminiscent' subjects :

Blot 7 suggested a crown: he said,

"I seemed to be back in the Tower of London looking at the Crown Jewels. $I$ could see the bars in front of them, and the men guarding them. I didn't see myself there, but I felt as if I was there. It was Sunday afternoon. You seem to feel different on Sunday somehow, and I felt like that."

Another blot he called two ' robins':

"That reminded me of a picture in a book called Chatterbor that I used to look at when I was very young. It is queer because $I$ had really forgotten all about that picture. Now I come to think of it the birds there were not robins at all. But they were standing just as these two are here."

Blot 6 was 'Coto bark':

"That is exactly like a particular specimen of coto bark I saw not long ago. All the circumstances came back vividly to me. I was in the laboratory, and I seemed to see the faces of a lot more men who were there too."

Blot 11 he called a pansy:

"I remembered a Sunday afternoon at Ryde when I was reading a book about a pansy. There was something peculiar about the stigma of this particular flower, and I was specially interested in it. The image of the book came back to me. I could see its green covers. I was sitting in a chair just like this one; with crossed legs, leaning against one of the arms exactly as I am doing now. The author's name came back to me, but not just at first."

This subject had, he said, distinct visual imagery throughout, but never of himself. He came into the scene through having what he called 'the feel of' an experience. This was common in other cases also, particularly when what was recalled had occurred long before. For blot 3, for instance, one of the 'reminiscent' subjects wrote: "Feel shuddery-a conglomeration of slimy snails." Then she said that many years before, at a boarding-house at the sea-side, she had suffered a shock on finding a snail crawling on a bread plate. The feeling she had then was revived when she saw this blot, and became so strong that she had to turn away in disgust. Another subject was reminded by one of the blots of an operation for cancer that he had seen performed long before. He described how he had gone into an anatomical class-room not knowing what was the subject of demonstration. The sudden shock he had then was revived at the sight of the blot. 


\section{Some Problems of Perceiving and Imaging}

The feeling was by no means always painful. One 'reminiscent' subject called blot 8 a swallow, and the comment was :

"That is very curious. I associated the Square here [it was at a small town in Gloucestershire] with that, and it all came back to me how when I was a small boy of say 8 or 9 years I used to run after the swallows, and try to catch them. It was nice to feel that again."

In all these cases it appeared that the first glance reinstated a more or less general situation, marked by a particular feel. Then specific details were developed. In this way suggestions that were not in the shape of the blot, such as suggestions of sound or of particular times and places, came in. Blot 1, for example, was once said to be a "cock crowing early in the morning," and the phrase "early in the morning' evoked the comment, "Well it has a very aggressive look, and I have been wakened several times lately by a cock-crow early in the morning."

Many subjects however showed a strong tendency to particularisation apart from much personal reminiscence. These often minutely specified their suggestions, dealing much in proper names and adjectives. Such subjects would not say "rat' simply, but " a particularly venomous rat"; not 'duck' simply, but "the duck I see is standing on its legs running, flapping its wings and quacking"; not simply 'a man walking,' but things like " Peary going to the Pole." Often the suggestions were elaborate, with a kind of dramatic touch about them, as in "Girl leaning over some fence or bridge. Hat falls off. Cape blows back. Scarf flies up like a flag. She falls, screaming"; or "Miser's money bag with long strings. His saucepan ready for the fire by its side"; or "College crest in between two figures that are wrapped in sheets. Napoleon on the top of the crest." Quite often a blot suggested a picture, though not necessarily, as was the case in the proper reminiscent subject, the subject himself looking at the picture. Instances are: "That is like a picture of a camel I've seen in "Just-so Stories" "; "Very much like a picture $I$ have seen of a genius coming out of a bottle in 'Arabian Nights""; "It is a sunset with angelic figures coming through the clouds. Just like one of Blake's pictures" ; "Turner's 'Angel Faces.",

Subjects belonging to these first two classes were invariably quick at getting suggestions, very wide in their range, and they appeared highly amused throughout. They laughed readily, not so much at the queer shapes of the blots themselves as at the strangeness of the suggestions that occurred.

But there is a kind of particularisation that is of the blot rather than of the suggestion. In the instances so far considered there was 
a tendency to forget that something was given, because it was what was suggested that attracted chief attention. But here it was just what was given that was prominent. There may be little or no difference between the actual results secured in the two cases, but the second seems to be farther from imaging proper, and the behaviour of the subjects was distinctly different. In the second case there was much more sense of a problem, much less marked feeling, and in general a rather slower reaction. Very often this kind of particularisation occurred with suggestions that had to do with specialised scientific interests.

In the generalising subjects the feeling that was present seemed to attach not to the suggestions, or to the apprehension of the blots, or to any critical attitude with regard to the shape of the blot, but solely to the task itself of getting a suggestion. Subjects reacted more slowly, and there was a larger percentage of cases in which they could not get suggestions at all. What they got was unspecified and stood for any instance of its kind, but no instance was imaged or even thought of.

Most of these points are illustrated in the following complete list which was furnished by a 'generalising' subject ${ }^{1}$ :

$1[1]$. - 2. 2. Bird perched on something. $5[2]$. - 6. Potato sprouting. 7 [3]. Tadpole.

10. Canary on a perch. 11. Woman's head and shoulders.

3. Butterfly. 8. Bird. 12.

4. 9. Snails. 13. Moth. 14. Child walking. $15[7]$. Something burning. $16[8]$. Beetroot. 17. 18 [5]. - 19. Potato sprouting. 20 [4]. —. 21. Isle of Skye. 22. Two dancing bears. $23[9]$. - 24 [6]. Insect. 25. Two leaves. $26[10]$. A flower. 27. Leaves. 28. —. 29. —. 30. —. 31. —. 32 [11]. Paw marks. 33 [12]. Footmarks. 34. Sea anemone. $35[13]$. —. 36.

There was no visualisation with these responses, and with the single exception of suggestion 21 there was no specification. The subject was slow throughout, and took up a thoroughly disinterested attitude. With such subjects there was at times a marked puzzling to make out what the blots could represent, and this sometimes aroused a feeling which came near to annoyance.

It is notable that in the above list there is one definite specification: "Isle of Skye" for blot 21. The subject noticed this and said: "It isn't really like the Isle of Syke, but I was talking with a man about that yesterday." The particularisations of the generalising subjects had practically all to do with recent occurrences in this way.

1 The numbers given in this list refor to the order of blots as they were presented. The numbers in brackets refer to the reproductions in Plates I and II.

J. of Psych virI 
Of the generalising subjects three were students of philosophy who have had much training in abstract thinking, one was a mathematician, and the others were people whose general mode of life is regular and monotonous, who read comparatively little, and whose range of interests is not wide. Of the ' reminiscents' two were women who are accustomed to make up stories for their young children, one was a boy of 9 , one a boy of 13 , one a youth of 15 , and one a man of 22 who had just completed some years training for practical work in chemistry. The best of the particularising subjects were two men and one woman whose interests are dominantly literary and whose reading is wide.

\section{Discussion of Results.}

It is now time to attempt some discussion of the bearing of results obtained on the general theory of the nature and relations of perceiving and imaging.

The most impressive feature of the results of the first series of experiments is the great complexity which they showed to be present in much that we call perceiving. This has of course been noticed often enough before. In a "Study of Apperception"," for instance, Pillsbury gives a somewhat elaborate scheme according to which we have:

(1) the sensation, an element of all cognitive states, and admittedly an abstraction from concrete reality;

(2) the idea, a compound or complex of sensations;

(3) association, as giving the simplest form of connexion between ideas;

(4) apperception, as representing the influence of general experience in consciousness, just as association represents the influence of particular idea upon particular idea;

(5) perception, the first concrete conscious process from which all the other forms have been abstracted.

Thus Pillsbury maintains that perception, which he rightly speaks of as within itself a complete act, includes what are called assimilation, associative synthesis, and complication, all the forms, that is, of associative connexion that are discriminated by Wundt. It includes also the apperceptive connexion of apperceptive synthesis, and a good deal of what goes commonly under the name of thinking.

Now undoubtedly perceiving may include all this, but there is no reason for holding that it must. Pillsbury presented words for his subjects to read. His problems were therefore even less simple than

1 American Journal of Psychology, 1896-7, pp. 350-393. 
some of the earlier of those here given. Both in his case and generally in this, the subjects were adults whose acts are influenced by a mass of distinguishable mental processes. So that, although it is true that all such experiments on perceiving reveal very great complexity, what must be attempted is, not merely the sorting out and naming of distinguishable processes present in the most complex cases, but the decision of what is the minimum complexity possible, and how so large a number of factors come in in the course of development.

Very often in the mental life it is found that specific processes arise and serve relatively undirected general tendencies. That is the case bere. In all instances of perceiving there is what has here been called an 'effort after meaning,' and the many definite processes that may be discriminated within a developed act of perceiving are to be thought of, not so much as constituents of the act, but as ways in which the 'effort after meaning' finds expression in the presence always of direct sense stimulation, for without the latter we cannot speak of perceiving at all.

The term 'effort' does not mean that in all, or indeed in any, acts of perceiving the subject feels himself striving in any way. It is used because in no case is perceiving merely a receiving of something given: there is always some discrimination and selection; and because it is a convenient word to indicate a tendency that while it takes many specific forms retains its general nature throughout'. It is by virtue of the latter characteristic that imaging and thinking may both be considered parts of a total act of perceiving in some cases.

The term 'meaning' is equally important. As Hönigswald says, "The factor of meaning (Sinn) cuts deeper and deeper into the enormous complexity of the psychic life as the dominating reaction ${ }^{2}$." Here it indicates the presence of at least two directing factors in all attention

1 It has been suggested that in spite of the truth of these considerations ' effort' is not quite the term that should be used. Under ordinary circumstances, it is said, nothing is more effortless than pereeiving, and it would be better to use some such phrase as 'tendency to find meaning.' The word 'tendency,' however, is hardly definite enough to name the factor here referred to, and so long as the implication of strain is kept away there seems to be no valid objection to the retention of the term 'effort.'

${ }^{2}$ Prinzipien der Denkpsychologie, quoted by Ewald: The Philosophical Review, Vol. xxiII. p. 619: "The circumstance," he goes on, "which seems to me to demand the most serious consideration, even from a purely psychological point of view, is the tendency of everything psychical in the direction of meaning, or what I should like to call simply the 'meaning' of the psychical.... Only the relatively meaningless can have a place in the psychic structure; and the striving after a meaningful connexion for elements in an unmeaning juxtaposition probably ceases only with the end of the psychic life itself." 


\section{Some Problems of Perceiving and Imaging}

to a present object: $(a)$ the readiness with which an act of apprehension is itself carried through, and $(b)$ a certain undefined experience of familiarity in reference to the presented situation. These two are most closely connected, so that often $(a)$ depends on $(b)$, while $(b)$ itself is the direct outcome of the fundamental characteristic of retentiveness. All the various processes of associating and of apperceiving are ways in which the experience of familiarity is rendered definite, and they come to be parts of an act of perceiving because of the persistency of the 'effort after meaning.'

Apart then from the attribution of meaning there is no perceiving, but meaning may be attributed either in a very vague or in a very definite manner. In the former case there is a tendency to speak of the experience as a 'feeling of' something. What the attribution of meaning is at its minimum the experiments throw no light upon, but they do illustrate how, when meaning is vaguely attributed, there is a tendency to speak of it as a feeling. This is the significance of the fact that subjects often said that they "felt" that what they saw represented something, and of the 'feeling of relation' present particularly in connexion with symmetry.

This 'feeling' however is not feeling proper, though it is accompanied by that, but it is really vague apprehension, either in the first place of some thing or in the second place, when analysis begins, of certain relations. By development of the first we get all the marks of imaging, and of the second all the marks of thinking. The two, in fact, proceed together.

So far as these processes of development are met with at all in experiments they are already in mid-course. A simple situation-a diagram or a picture-is presented, and is seen as a whole. But there is always a tendency to see it as an instance of something, and this may be so clear that the subject gives the object a name. Befinite naming, of course, requires that much work of analysis and synthesis, much recognition of likeness amid difference, shall have been carried out, and so itself indicates considerable development. But, as in these experiments, there are plenty of cases in which a subject, without definitely giving a name, will say that he has an impression that what is presented is an instance of something. This impression seems capable of analysis into $(a)$ an apprehension of what is given, and $(b)$ a feeling not quite definite enough to be called a feeling of familiarity, but rather merely of the relative ease with which the act of apprehending is earried out. The latter is a true feeling, attaching to the whole act, and not 
a vague apprehension - called a feeling only because of its vaguenessof relations of parts within an object. This feeling may have a good deal to do with the influence of general experience upon perceiving, and at any rate is at the foundation of much imaging.

For all acts of perceiving yield the familiar analysis into act, object and content, the relation of act and object in this case being brought about always by means of sense experience. Specifying the content, and accompanying the whole act, is a feeling which 'may originally be one merely of relative ease or hesitation, but which very rapidly takes certain quite definite forms, and in these experiments appears as satisfaction, familiarity, surprise, disgust, and so on. It is the feeling which, upon a repetition of the same general situation, plays a leading part in tending to reinstate the content. But at first, since the feeling qualifies the act as a whole, it is the whole content in all its particularity that tends to be reinstated. The image proper is as concrete and individual as the percept. In the last of the series here employed all the subjects in whom imaging was most clear and precise were persons with dominantly concrete interests, and in many cases the imaging was induced largely by some particular feeling, together of course with the apprehension of what was presented.

But though the content, in an act of imaging proper, is always capable of precise localisation, at the same time it is far more fluid than that of an act of perceiving. In perceiving we say "that is soand-so," but in such cases of imaging as we have in the last series we say commonly "that may be this, or this, or something else.". Moreover transpositions in imagery are much more common than are generally supposed. Consequently images are all the time tending to lose their particularity.

The basis of this is the development of analysis which gets its earliest illustration, so far as the present experiments go, in the 'feelings of relation.' As has been said already these are not feeling proper at all. They do not simply accompany an act, but indicate rather that the act is now directed, not upon the object as a whole but upon parts of it, so that the content holds together detail, at first vaguely, but then with more and more definiteness. And this apprehension of relations is the basis of the generalisation which is the chief mark of thinking1.

1 P. 14. See also Höffding: Modern Philosophers and Lectures on Bergson (Eng. trans.), pp. 256-7. Höffding uses the term "analytical intuition," and points out that Descartes and Poincaré have described it, and that "it designates for them the very passage from perception to analysis or proof." 


\section{Some Problems of Perceiving and Imaging}

For this analysis, indefinite as it is, means that a part of what is presented, having relations to other parts, may, on its recurrence, constitute for the subject much the same general situation as would the recurrence of the whole. And then what is not presented to sense, since nevertheless it is reinstated for experience, is already relatively free from a set context. But the constant change of life continually presents relations of sameness, difference, relative position, and so on, with immense variation of material; and so it comes about that the recurrence, for sense experience, of parts of an object tends to reinstate, for imaging, wholes very different in character. This itself tends to damp down the feeling characteristic, for feeling conspicuously attaches itself to particular wholes. At first, when suggestive material is presented, as in Series 4 and 5 here, this often induces the subject to say: "That is this, or this, or this"- there is a rapid alternation of suggestions. But all the while the processes of analysis are going on, the relations of the various suggestions are noted, their points of similarity are grouped together, and the suggestions narrow to a whole, relatively unqualified by feeling, which is itself capable of much specification. This is the stage of the generalising subject of the last series, and comes far nearer to thinking than to imaging proper. To fix both specifications and generalisations naming is important, and hence the prominent part it played throughout the experiments.

In a complete act of perceiving then, imaging, as the reinstatement of a situation or object not presented wholly to sense experience, and thinking, in its beginnings as an apprehension of relations apart from the nature of what is related, may both be found. They both involve the partial freeing of a content from sense background, and this may go farther, so that the processes take place in the absence of sense stimulation altogether. Imaging however always tends to retain a characteristic definiteness of content, and to occur in close connexion with strongly marked feeling. Thinking may achieve equal or greater definiteness, but the definiteness always appears as a characterisation of that which is thought about, and feeling is at a minimum.

If this analysis is on the right lines, then all attempts to find original constituents of mental life are wrong-headed. There are doubtless specific feeling-attitudes of, say, satisfaction, surprise, disgust and so on. These, so far as they are thus definite, appear all to have developed out of feeling-qualification that is much more vague, and the experiments show how quickly they tend to develop. But in any case they are not material out of which the mental life is made. They are found alike 
with perceiving, with imaging, with thinking, with willing, with any kind of reaction of a conscious subject to environment, and are simply ways in which such reaction is qualified.

Similarly there are specific ways in which acts of perceiving, of imaging, and of thinking may proceed, and some of these have been given in the summary of results in the earlier part of this record. But the acts themselves are no more made up of them than they are made up of those features in the objects themselves that facilitate perceiving or imaging. We have no right whatever to speak of original sensations, or percepts, or images, or ideas from the putting together of which a man is made. When, for instance, Karl Bühler, finding good evidence for the existence of acts of thinking entirely unaccompanied by images, speaks of elementary Gedanken, and cites in illustration the appreciation of Gestaltqualitäten which, he thinks, proceeds in early cases by an intellectual apprehension of the meaning (Sinn) of a presented figure, what he has found is that in a total act of perceiving there already may be the beginning of the process of analysis. That is true enough. But if then we go on to speak of original specific feelings, of original distinct percepts, and of original thoughts, and try to build them together into a life, we are hopelessly astray.

At the beginning of this paper some of the difficulties of the search for the simple were mentioned. It is now clear that what we want is not a number of simple elements out of which at the must we could construct a toy for psychologists to play with, but a knowledge of the minimum of conditions under which an effort after meaning of a specific character can take place, and further of the ways in which such distinguishable efforts are themselves related.

\section{Summary.}

We see then that under many different conditions, and in many different forms, the fundamental 'effort after meaning' is found. And we have to try to say what form is present under what conditions. At first, always, there must be immediately present sense experience, and then we have an act of perceiving. This however itself takes place under many diverse circumstances, and some of the forms of perceiving and their conditions were brought out in the early parts of the paper. Largely, however, through the feeling that accompanies all effort to attribute meaning, and through the analysis of which this 


\section{Some Problems of Perceiving and Imaging}

feeling may be the basis and which is found anyhow in the perceiving of all developed subjects, we soon come to be able to go beyond immediate sense experience, though that is a complication which at once saves time and increases the chance of error. Then we get, first imaging, in such forms and under such conditions as were illustrated in the second part of the paper, and eventually thinking, all three processes being commonly closely connected. In imaging feeling proper plays a dominant part, and as this tends always to be attached to a whole situation, the content of an act of imaging always tends to be particular and capable of precise localisation. But then, perhaps mainly through lack of variety of experience, or maybe by the great growth of a positive interest in analysis - for these two may produce substantially the same results when these results are viewed merely from without-imaging tends to become less and less definite, and more and more general. At that stage this investigation ceases. Before any definite study of the conditions and forms of thinking proper can be made, it will be necessary to consider the evidence for the fluidity of the content of imaging, and the various forms of transposition that imaging constantly illustrates, and that lead to all kinds of conventional representation'.

There is one other point. In the feeling which plays a prominent part in freeing content from immediate background of sense, and so in determining early forms of imaging we have the foundation, probably, of all criticism and valuation. Yet it is only in thinking proper, where we are commonly away from the particular, and so freer from feeling than we are under any other circumstances, that criticism is usually considered to reach its highest development. Here also is a problem for further study.

1 Cp. Philippe: “Sur les Transformations de nos Images Mentales," Revre Philosophique, 1897, pp. 481-93 : “L'image est mobile," he says, "et vivante, et soumise a de perpétuels changements sous l'incessante action de nos sentiments ou de nos idées." Philippe indicates certain common general ways in which images undergo transformation, but his study is preliminary only, and the whole subject calls for more detailed experimental investigation. 
JOURNAL OF PSYCHOLOGY, VOL. VIII, PT. 2.

PLATE
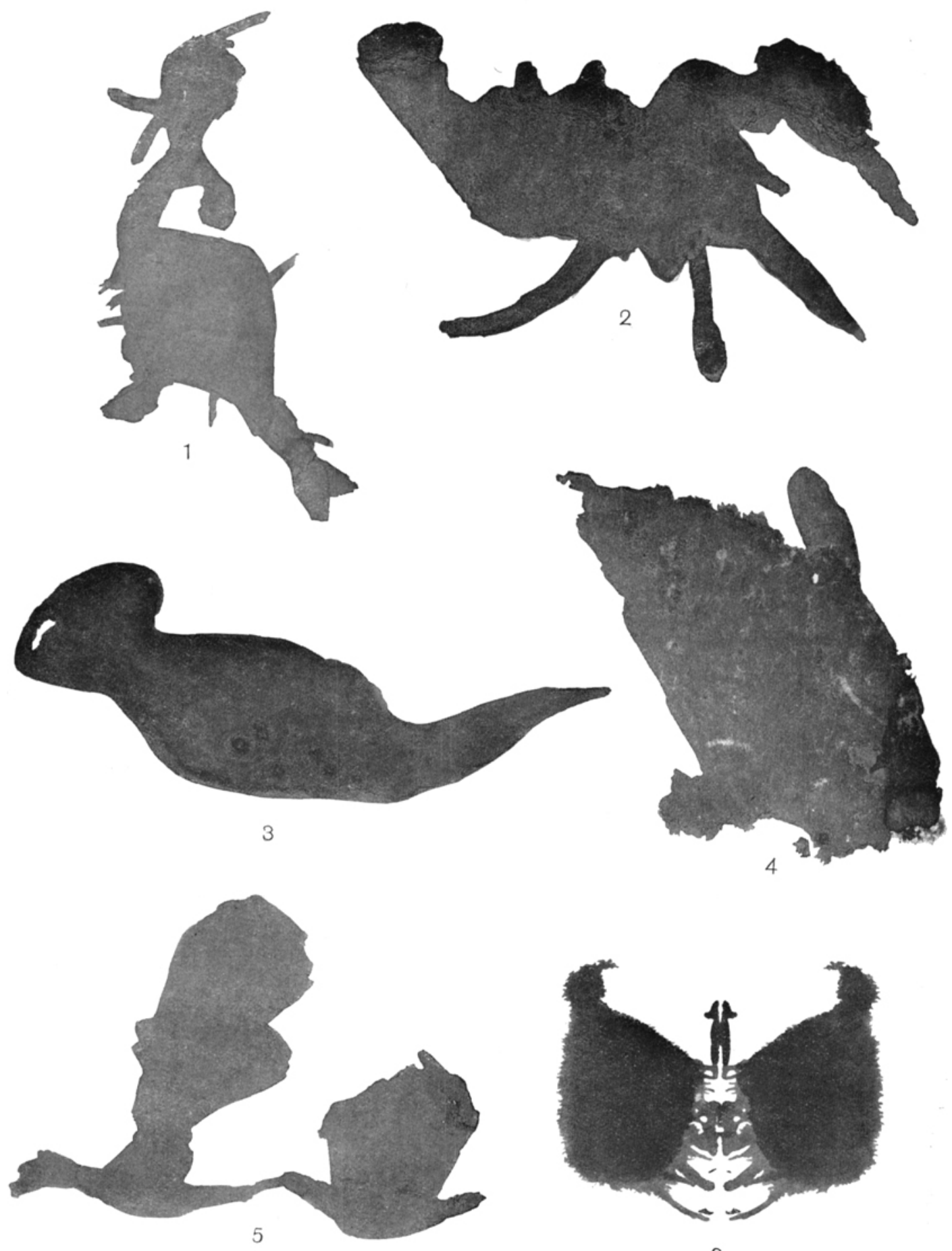

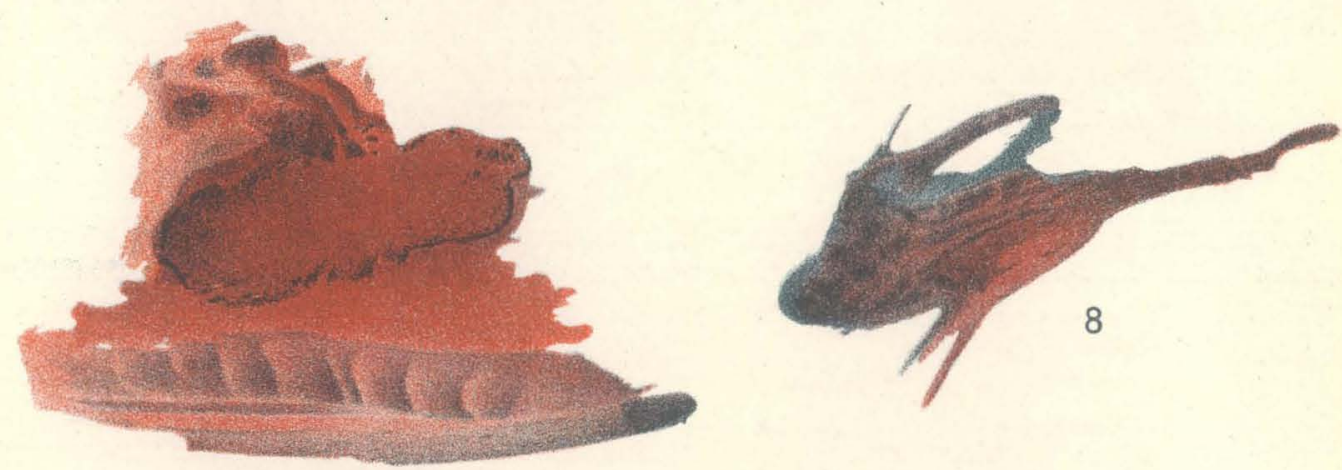

7
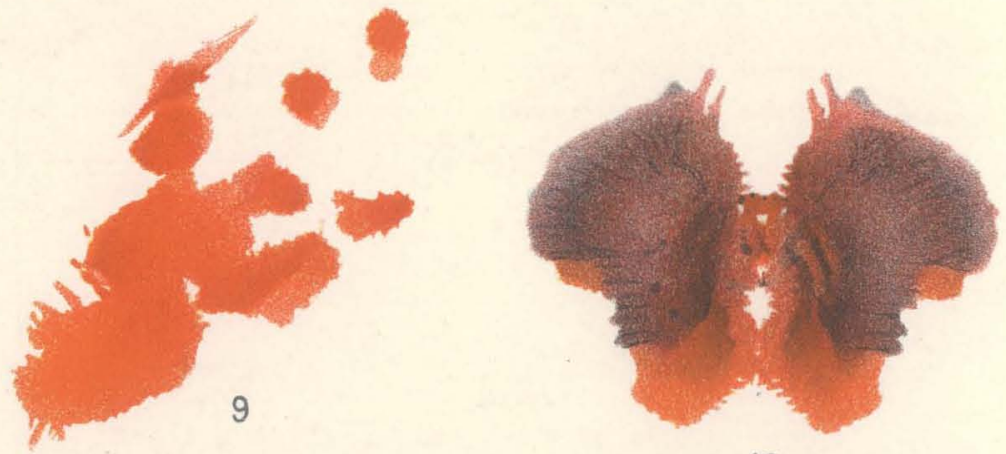

10

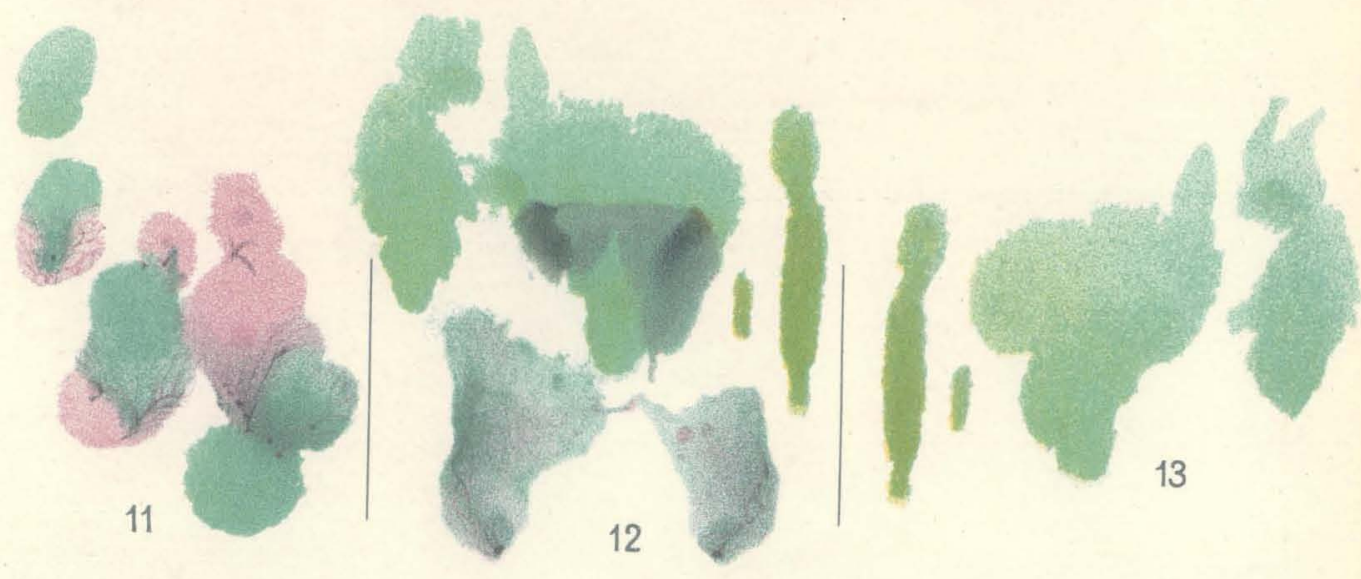

